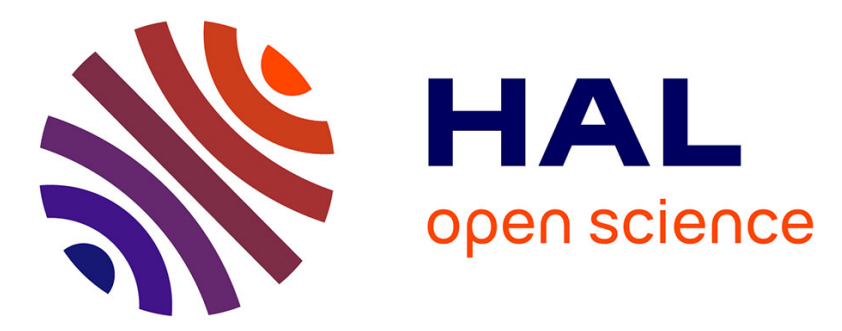

\title{
Automated detection and characterization of diffraction curves in WISDOM/ExoMars radargrams
}

\author{
Nicolas Oudart, Valérie Ciarletti, Alice Le Gall, Yann Herve
}

\section{To cite this version:}

Nicolas Oudart, Valérie Ciarletti, Alice Le Gall, Yann Herve. Automated detection and characterization of diffraction curves in WISDOM/ExoMars radargrams. Europlanet Science Congress 2021, Sep 2021, Online, Unknown Region. pp.EPSC2021-293, 10.5194/epsc2021-293 . insu-03550122

\section{HAL Id: insu-03550122 \\ https://hal-insu.archives-ouvertes.fr/insu-03550122}

Submitted on 31 Jan 2022

HAL is a multi-disciplinary open access archive for the deposit and dissemination of scientific research documents, whether they are published or not. The documents may come from teaching and research institutions in France or abroad, or from public or private research centers.
L'archive ouverte pluridisciplinaire HAL, est destinée au dépôt et à la diffusion de documents scientifiques de niveau recherche, publiés ou non, émanant des établissements d'enseignement et de recherche français ou étrangers, des laboratoires publics ou privés.

\section{(c)(1)}

Distributed under a Creative Commons Attribution| 4.0 International License 


\title{
Automated detection and characterization of diffraction curves in WISDOM/ExoMars radargrams
}

\author{
Nicolas Oudart ${ }^{1}$, Valérie Ciarletti ${ }^{1}$, Alice Le Gall ${ }^{1,2}$, and Yann Hervé ${ }^{1}$ \\ ${ }^{1}$ Université de Versailles Saint-Quentin, LATMOS, PLANETO, Guyancourt, France (nicolas.oudart@latmos.ipsl.fr) \\ ${ }^{2}$ Institut Universitaire de France, Paris, France
}

\section{Introduction}

WISDOM (Water Ice Subsurface Deposits Observation on Mars) will be the Ground Penetrating Radar of the Rosalind Franklin rover of the ExoMars 2022 mission. This rover will be the first able to collect samples down to $2 \mathrm{~m}$ in the Martian subsurface, and analyse them in search of potential traces of life [1]. Prior to any drilling operations, the WISDOM instrument will provide an insight into the shallow subsurface structure and composition, in order to guide the sample collection and understand its geological context [2].

In order to guide precisely the rover drill, an accurate estimation of the speed of electromagnetic waves in the subsurface is required to convert time delays of echoes from underground interfaces into distances. In the case of subsurface materials to be sounded by WISDOM, this speed is expected to be directly driven by their dielectric constants. Additionally, before drilling, subsurface hazards such as buried boulders must be detected by WISDOM to be avoided.

The automated interpretation chain we developed will be able to detect diffraction curves corresponding to potential subsurface hazards in WISDOM radargrams, and characterize the shape of these diffraction curves to estimate the dielectric constant of the subsurface, and therefore the depths of the hazards.

For most GPR radargrams operating on Earth, the antennas being directly coupled to the surface, the diffraction curves from point scatters are mathematically perfect hyperbolas (see Figure 1). In the case of WISDOM, the engineering constraints of the ExoMars mission imposed a distance of 38 $\mathrm{cm}$ between the bottom of the antennas and the Martian surface. In this air-coupled situation, with the refraction of electromagnetic waves at the surface, the diffraction curves are no longer perfect hyperbolas [3], and another model is required (see Figure 2). 


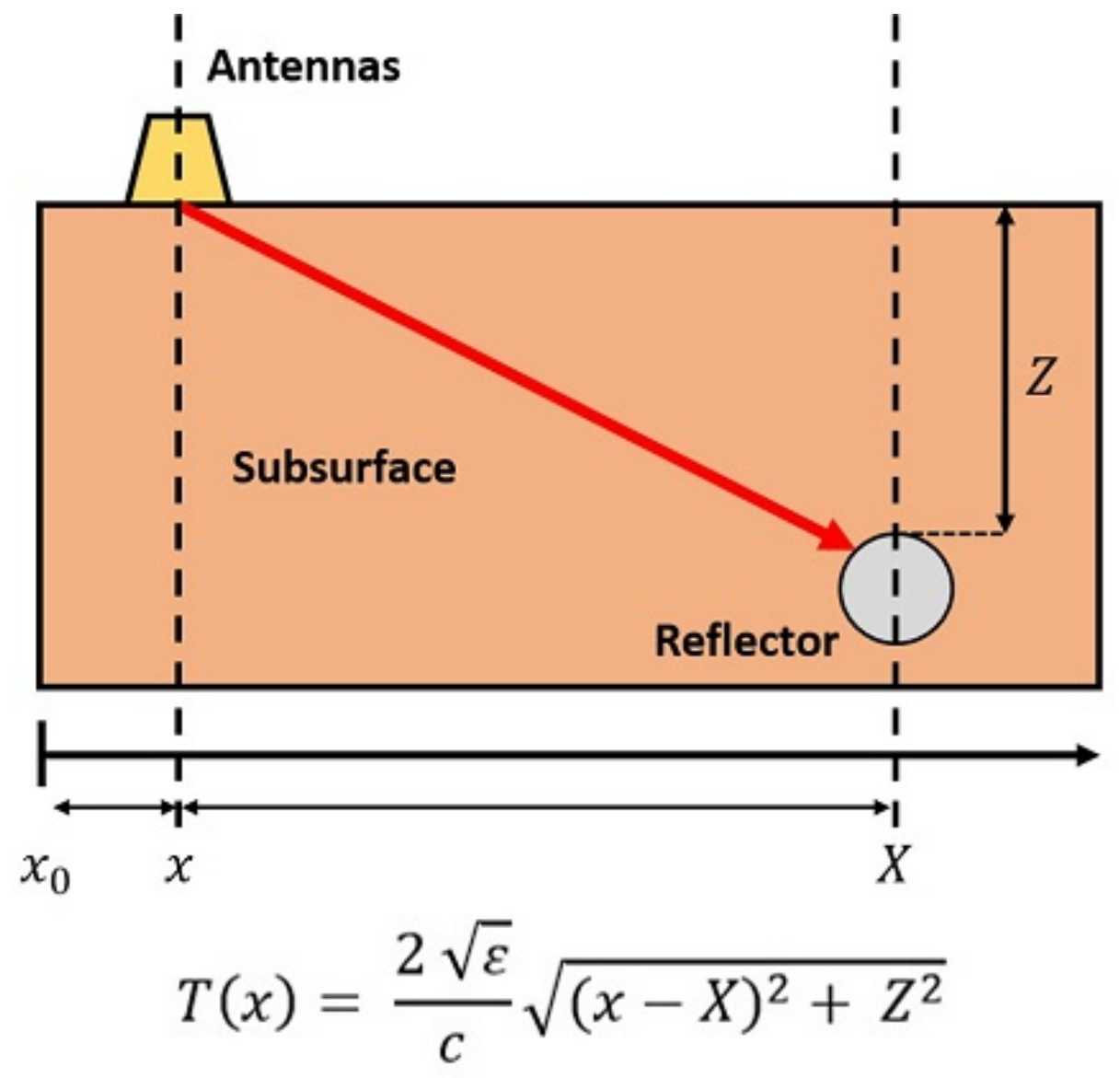

Figure 1. Models for the diffraction curves in the ground-coupled set-up

As a consequence, we adapted the Hough transform that was already implemented to detect hyperbolas in GPR radargrams in ground-coupled situations [4], for the detection of diffraction curves in WISDOM radargrams. Promising preliminary results have been obtained on numerically simulated radargrams, and applications to experimental radargrams is ongoing. 


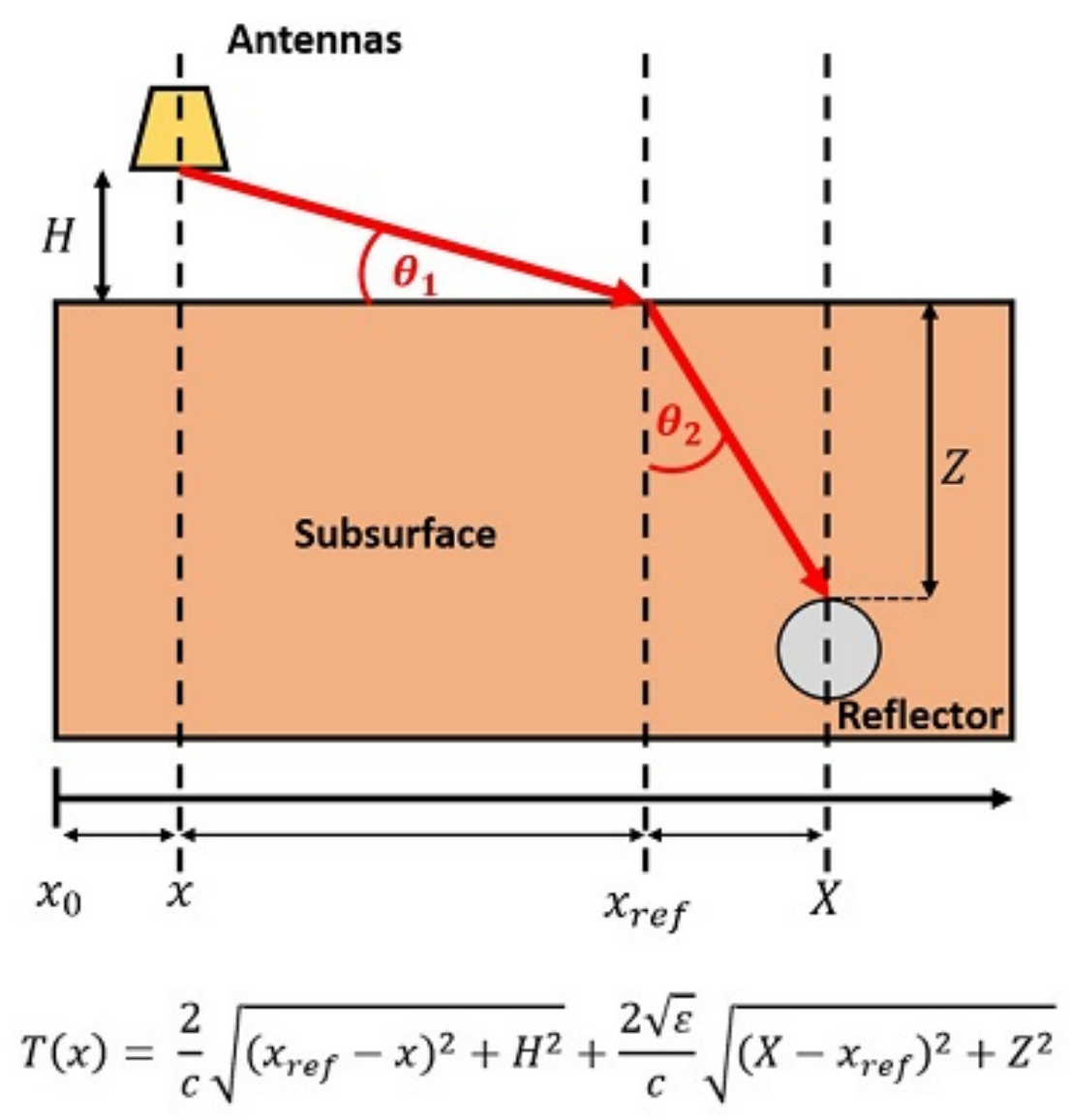

\section{Figure 2. Models for the diffraction curves in the air-coupled set-up}

\section{Method}

The Hough transform is a classic image processing technique, originally invented to detect lines in an image, and later adapted to the detection of any shape with an analytic definition, such as hyperbolas. The idea behind the detection of hyperbolas is the following one: any hyperbola can be defined by a unique triplet of parameters, or by any triplet of points in the hyperbola. For a hyperbola in ground-coupled GPR radargram, the 3 parameters are the horizontal position of the antennas $X$, the time delay at the apex of the hyperbolas $T$, and the dielectric constant of the subsurface $\square \square$.

First a detection of echoes is applied to the radargram, to obtain a cloud of points with horizontal and vertical positions corresponding to the horizontal distance and time delays of these echoes. For every triplet of points in the radargram, the parameters $(X, T, \square \square)$ of the hyperbola passing through this triplet is calculated, and a $3 \mathrm{D}$ accumulator is incremented +1 at the position corresponding to $(\mathrm{X}, \mathrm{T}, \square \square)$. Maxima in the accumulator are expected to correspond to the hyperbolas present in the radargram.

To adapt the technique to WISDOM radargrams, where diffraction curves are not perfect hyperbolas, the presented "air-coupled" model had to be employed to determine a first estimate of parameters $(X, T, \square \square)$ of the diffraction curves corresponding to the different triplets of points. The equation presented in Figure 2 being far more complicated to analytically inverse than the equation of a hyperbola, an optimization technique (the Nelder-Mead algorithm [5]) is used. 


\section{Preliminary results}

In order to validate the technique before its application to experimental WISDOM radargrams, different numerical simulations (with a Finite Difference in Time Domain code) have been performed on subsurface models with a selected homogeneous dielectric constant, and buried targets. The geometry of the antennas, and the equivalent time-domain signal emitted by the radar have been modelled for these simulations to be as representative as possible of the WISDOM radargrams.

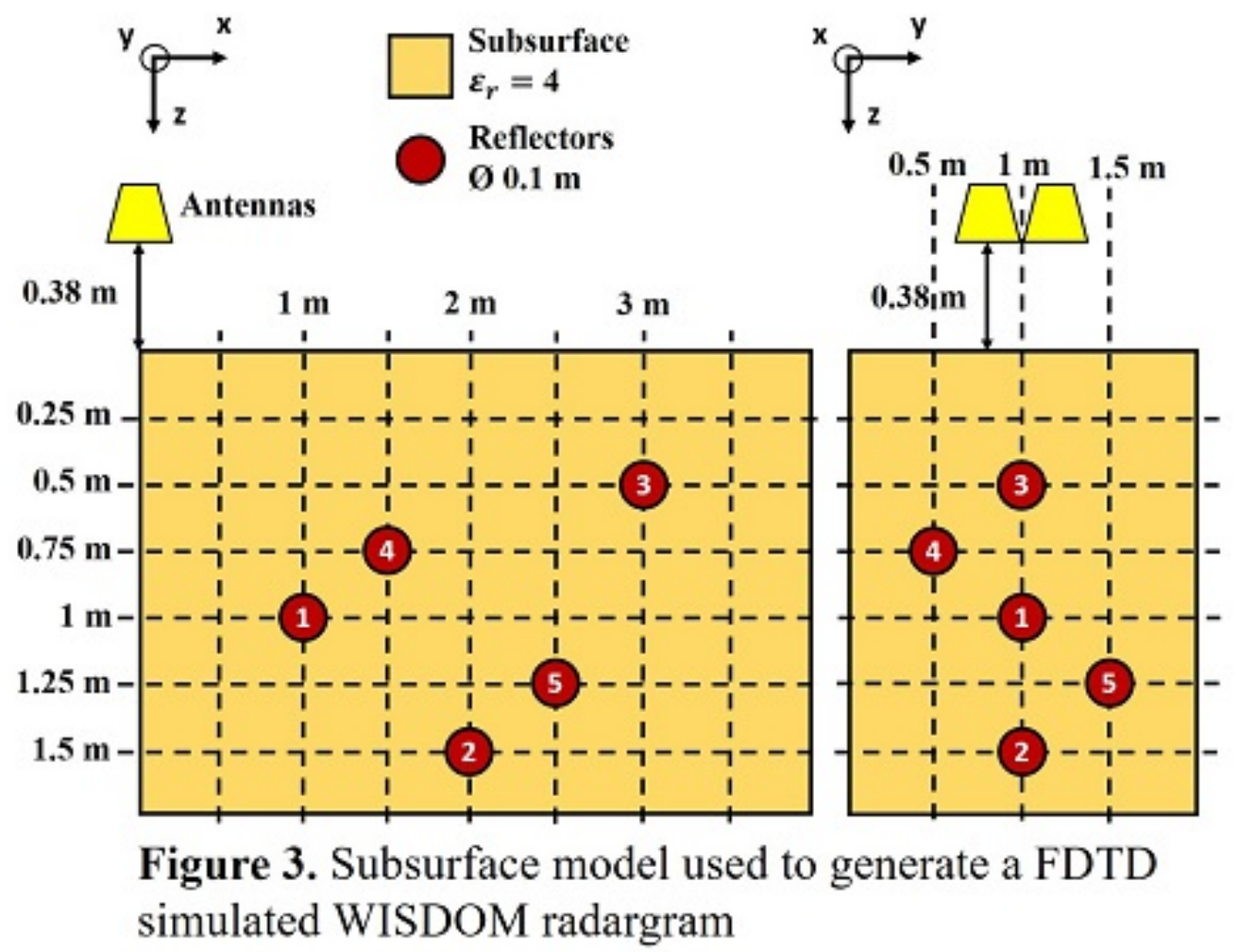

As an example, we show here a simulation generated for 5 underground targets in a subsurface of dielectric constant 4 (see Figure 3). In addition to the echoes detected in the simulated radargram, 500 parasitic points with random positions have been added to the cloud of points to which we applied the Hough transform (see Figure 4). The idea is to see if the implemented tool is able to detect diffraction curves among other echoes. 


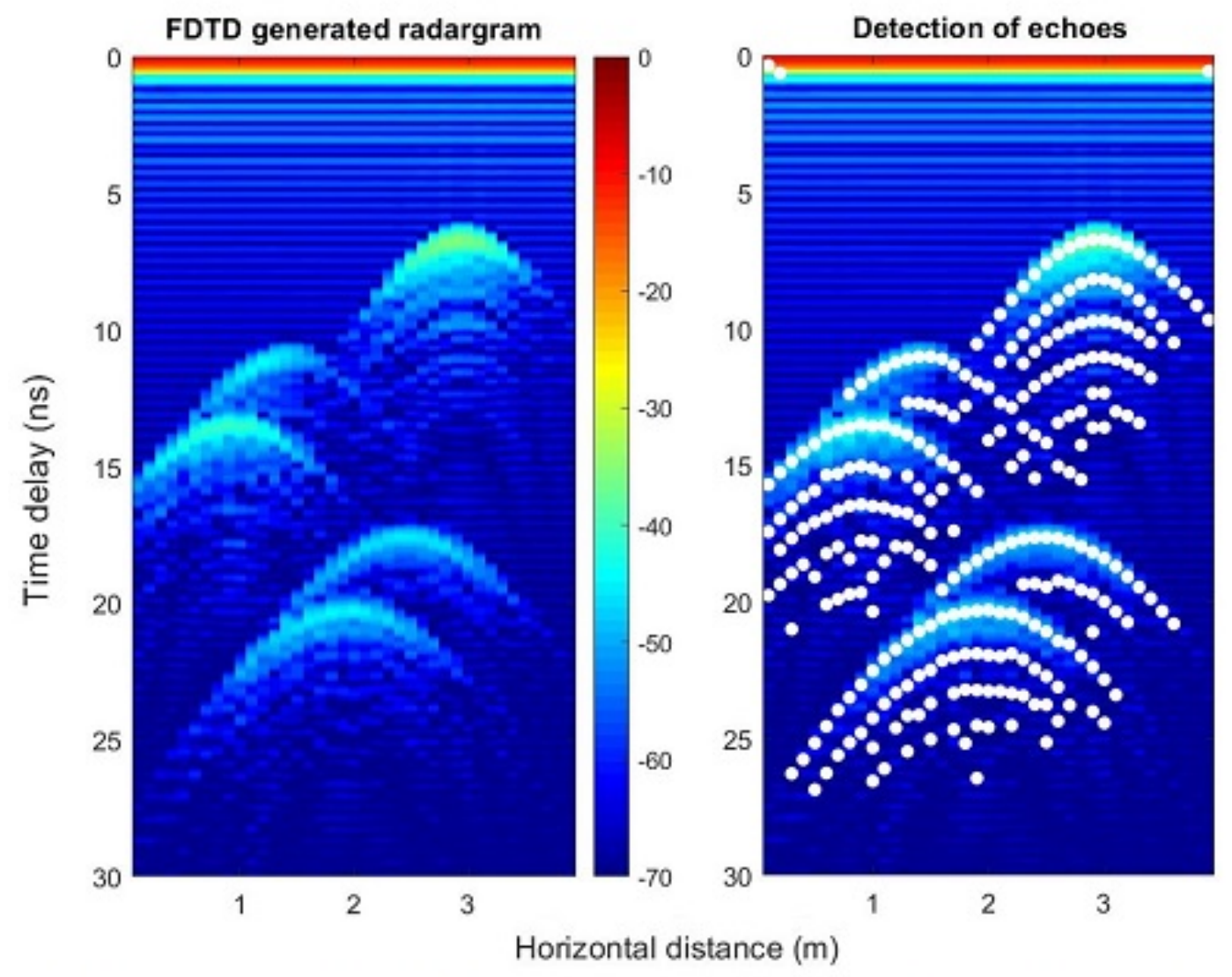

Figure 4. Simulated WISDOM radargram and echoes detected in this radargram

With the classic Hough transform (using the model presented in Figure 1), the estimated dielectric constants were 1.3, 1.8, 2.2, 1.9 and 2.3, leading to estimated depths of $0.88,1.23,1.47,1.78$, and $2 \mathrm{~m}$, to be compared to the expected $0.50,0.90,1,1.35$, and $1.5 \mathrm{~m}$. An over-estimation of the depth of a subsurface hazard could obviously be dangerous for the rover drill during the ExoMars 2022 mission.

After the application of the corrected Hough transform we implemented, the estimated dielectric constants are 4, 3.8, 3.8, 3.7 and 3.8 (much closer to the expected 4), and the estimated depths are now $0.50,0.85,1.04,1.37$ and $1.56 \mathrm{~m}$ (see Figure 5). The estimation is now accurate with error levels of only a few $\mathrm{cm}$. This result validates the ability of the implemented technique to automatically detect diffraction curves in WISDOM radargrams, accurately estimate the dielectric constant of the associated subsurface material, and eventually estimate the depth of the associated reflector on Mars. 


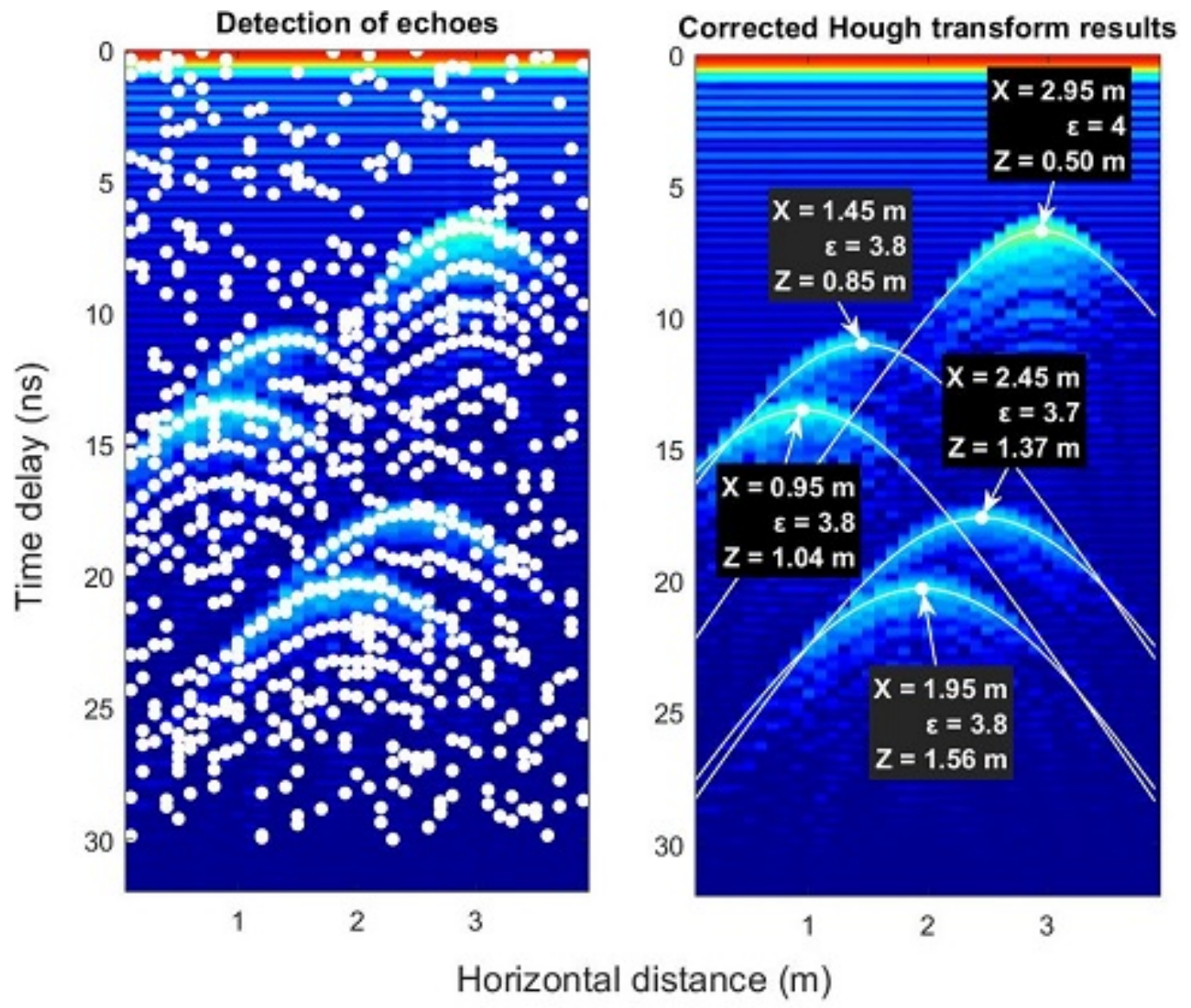

Figure 5. Detection of echoes with 500 parasites in the simulated WISDOM radargram, and the results of the corrected Hough transform we implemented

Will be presented the results of this interpretation tool applied to other simulations, some of them generated with more complex subsurface models (heterogeneous materials, two underground layers...), and eventually to experimental WISDOM radargrams where diffraction curves are visible.

\section{References}

[1] Vago et al., Astrobiology, 2018

[2] Ciarletti et al., Astrobiology, 2018

[3] Persico et al., Near Surface Geophysics, 2015

[4] Capineri et al., Imaging Systems and Technology, 1998

[5] Nelder and Mead, Computer Journal, 1965 